\title{
Отражение экспрессивного звучания стиховой речи в художественном переводе
}

\author{
МИХАЙ ПЕТЕР \\ PÉTER Mihály, ELTE Orosz Nyelvi és Irodalmi Tanszék, H-1088 Budapest, Múzeum krt. 4/D. \\ Department of Russian Language and Literature, Faculty of Humanities, Eötvös Loránd University \\ E-mail:peter28@mail.datanet.hu
}

(Received: 7 September 2018; accepted: 8 November 2018)

\begin{abstract}
The present paper gives a positive answer to the question about the possibility of adequate poetic translation. It presents extracts of Russian poetry that contain various phonic devices (e.g. rhythmic variations, sound repetitions, vowel alternations, consonant clusters, etc.) which, in addition to other verbal means, make up the peculiar aesthetic value of a poetic work. The Hungarian translations of the extracts from Pushkin's The Bronze Horseman and Eugene Onegin, Tyutchev's Autumn Evening, and Tvardovsky's Vassili Tyorkin, made by the prominent poets and translators Lajos Áprily, Árpád Galgóczy, and Lőrinc Szabó, masterly reproduce the phonic qualities of the Russian texts, and prove the validity of the Pushkinian claim on the "alliance of sound, thought, and sentiment" in lyric poetry.
\end{abstract}

Keywords: Russian poetry, expressive phonic elements, Pushkin, Tyutchev, Tvardovsky, Hungarian translation

1. Издавна разделяются мнения относительно возможности адекватного художественного перевода поэтических произведений. Представители скептических суждений ссылаются на то, что семантический мир и грамматическая система двух языков никогда полностью не покрывают друг друга, а также на то, что любое стихотворение является уникальным, неповторимым продуктом. По меткому сравнению американского ученого У. Уинтера, нельзя создать точную копию мраморной статуи в глине или бронзе (Чуковский 1964: 167-168). Более осмотрительным в свое время был подход основоположника общего языкознания, В. Гумбольдта, который считал, что разные языки, подобно словам-синонимам, выражают одно и то же понятие несколько по-разному, с тем или иным побочным значением, на более высокой или низкой степени шкалы эмоций. В то же время ученый признал поэтический перевод одной из наиболее необходимых деятельностей для данной литературы, так как он представляет иначе недостижимые формы искусства для людей, читающих только на своем языке. Кроме того, Гумбольдт утверждал, что перевод важен для расширения значений и выразительной силы своего языка (JÓZAN-JENEY-HAJDÚ 2007: 150-151). Выдающийся филолог Е. Эткинд снимает противоречивость проблемы перевода, предлагая двойную характеристику переводчика: «Поэту-переводчику приходится сочетать... самое чистое и высокое вдохновение художника с самым точным, скрупулезным, педантичным трудом исследователя. Только такое соединение искусства и 
науки... сулит переводчику подлинный успех» (Эткинд 1963: 70). Таким образом, переводчик поэзии - это двуликий Янус, действующий у входов и выходов словесного искусства разных народов.

2. Поэтическое содержание лирического стихотворения обнаруживается только частично в обыкновенном (поверхностном) прочтении его текста; оно представляет сложное художественное целое ритма, инструментовки, синтаксического и стилевого строя стихотворения, эксплицитных и имплицитных значений его лексических элементов (ср. Эткинд 1963: 269). По исключительно сжатой и точной формуле А. С. Пушкина, поэтическое содержание выражается в союзе «волшебных звуков, чувств и дум» (Евгений Онегин, I: 59). Под «звуками» должны пониматься эстетически действенное звучание стиха, его инструментовка, звукопись, различные звуковые повторы (включая и рифмы), и не в последнюю очередь его ритмическая организация, составляющие совместно с словесным материалом и его расположением своеобразную интонацию, «музыку» текста.

Отдельные звуки речи не имеют денотативного значения. Но, благодаря своим артикуляционным и перцептивным особенностям, звуки обладают некоторыми чертами, которые вследствие нейропсихического явления синестезии могут выражать противоположные пары качеств типа светлый-темныци, мягкий-твердый, легкий-тяжельй и др. Хотя в повседневной коммуникации этот звуковой символизм находится обычно в скрытом виде, в поэтической речи он выступает наружу и может заметно участвовать в создании поэтического содержания. Несмотря на то, что артикуляционная и перцептивная база отдельных языков более или менее сильно различаются, эти общечеловеческие факторы звукового символизма во многих случаях допускают действенный перевод художественной звукописи с одного языка на другой.

Ниже я привожу несколько наглядных примеров перевода «звука» русского стихового оригинала на венгерский язык. При этом, разумеется, нельзя оставлять без внимания метр поэтического текста и его ритмических вариаций, так как ритм является основной связывающей силой всех остальных компонентов художественной цельности стихового текста.

3. Вот три отрывка из Вступления к поэме Пушкина «Медный всадник» и их переводы, сделанные Арпадом Галгоци. В отрывках «А» и «Б» звукопись содействует стилистически возвышенному представлению великодержавных стремлений Петра Первого и его планов о построении новой столицы империи. Отрывок «В» посвящен обобщенному изображению великосветской жизни Петербурга.

(A)

...И думал он:

Отсель грозить мы будем шведу.

Здесь будет город заложен

На зло надменному соседу.
S ö így tervezgetett:

Innét szegzünk fegyvert a svédre, Itt város lesz a part felett

A dölyfös szomszéd ellenére. 
Природой здесь нам суждено

В Европу прорубить окно,

Ногою твердой стать при море.

Сюда по новым им волнам

Все флаги в гости будут к нам,

И запируем на просторе.

(Б)

Люблю тебя, Петра творенье.

Люблю твой строгий, стройный вид,

Невы державное теченье,

Береговой ее гранит,

Твоих оград узор чугунный,

Твоих задумчивых ночей

Прозрачный сумрак, блеск безлунный...
A lét rendezte úgy sorunk, Hogy Európára itt nyitunk Majd ablakot, megvetve lábunk A parton, s tengerünk szele Ha majd vendéget hoz, vele A síkon vígan lakomázunk.

Szeretlek, Péter alkotása, Tetszik komoly, szép küllemed, A Néva fenséges folyása, A parton hüs gránitköved, A cifra nyersvas kerítések, A halk, ábrándos éjszakák, Midőn az égen nincs szövétnek...

(B)

...И блеск, и шум, и говор балов,

А в час пирушки холостой

Шипенье пенистых бокалов

И пунша пламень голубой.

...Ha zaj kél fényes úri bálban, Ha víg legénytor kavarog, Ital pezseg fénylő pohárban, $\mathrm{S}$ a puncson kéklő láng lobog.

В этих трех отрывках встречаются шесть ритмических вариаций четырехстопного ямба; выделяются стихи с пиррихиями в третьей стопе: они создают особую, стилистически возвышенную интонацию (Hевы державное теченье // Береговой ее гранит). В двух стихах (Здесь будет город заложен... Все флаги в гости будут к нам) ямб заменен в первой стопе спондеем, выделяющим значения слов здесь и все. В переводе А. Галгоци ямбический метр несколько замедлен: ямбы представляют меньше чем половину стоп, их заменяют почти в $30 \%$ спондеи.

В отрывке (А) преобладают гласные заднего образования: 4 ударных и 9 безударных $y$ (из последних две гласных стоят в рифме: шведу-соседу). В отрывке (Б) имеются 6 ударных и 4 безударных $y$ и 4 ударных $o$; в отрывке (В) 3 ударных и 1 безударный у и 3 ударных $о$. Среди согласных преобладают губные и язычные $\sigma, n, \partial$; особенно экспрессивной является звукопись в стихах Шипенье пенистых бокалов // И пунша пламень голубой. Возвышенной торжественности стиля содействуют частые сочетания с дрожащим $p$ : pa, pe, pu, po, py.

Звукопись в переводе не достигает богатства оригинала. Удачны аллитерации в строках Tetszik komoly, szép küllemed, // A Néva fenséges folyása, хотя и не достигнуто органическое единство звучания и значения в определениях строгий, стройный. Но это единство полностью найдено в строках Ital pezseg fénylö pohárban, // S a puncson kéklö láng lobog, в которых повторяющиеся согласные $p$ и $l$ вместе с экспрессивными глаголами pezseg 'пенится', lobog 'полыхает' свидетельствуют о поэтической находчивости переводчика. 
4. Звукопись может играть важную роль в изображении различных видов движения, в частности танца. Две строки о молодом Евгении Онегине - Легко мазурку танцевал, // И кланялся непринужденно (I: 4) - настоящий перл вербального изображения движения; эффект достигнут органическим единством преобладающих сонантов $л$ и $\mu$, наречиями легко и непринужденно, и в первую очередь ритмитческими вариантами ямба с пиррихием на третьей стопе первой и на второй и третьей стопе второй строки. Перевод Л. Априли неплохой, хотя спондеи в пяти стопах делают его несколько тяжеловеснее оригинала: Könnyü lábbal táncol mazurt // És fesztelen tud meghajolni.

В первой же главе «Евгения Онегина» поэт виртуозно вербализует сложные фигуры танца, которые исполняет балерина Истомина:

Стоит Истомина; она...

Одной ногой касаясь пола,

Другою медленно кружит,

И вдруг прыжок, и вдруг летит,

Летит, как пух от уст Эола;

То стан совьет, то разовьет,

И быстрой ножкой ножку бьет.

(Евгений Онегин, I: 20) $\ldots$

A padlót most féllábbal érve, Másikkal lassan kört jelez, Majd szökken, száll és lengedez - Aeolus szája fújt pihére? Most megperdül s forog tovább S lábhoz lendül a fürge láb.

(Л. Априли)

Из семи строк, описывающих ее танец, четыре - сплошные ямбы, а в трех строках ямбы заменены пиррихиями в третьей стопе. В изображении артистических движений танцовщицы участвуют и синтаксические средства (короткие параллельные фразы И вдруг прыжсок, и вдруг летит; То стан совьет, то разовьет), слова прыжок, летит, и также дань классицизму: сравнение Kaк nyx om yсm Эола. Показ движений поддерживается чередованием передних и задних гласных (cmоит... кружит... летит и Одной ногой касаясь пола...; вдруг... nyx ... ycm). Сочетанием полного ямбического ритма с перекрестной аллитерацией согласных б и н (быстрой ножкой ножку бъет) мастерски передана фигура entrechat, т. е. прыжок, при котором балерина несколько раз ударяет ногою об ногу. В переводе Л. Априли преобладают экспрессивные глаголы движения (szökken 'прыгнет', száll 'летит', lengedez 'реет', megperdül 'завертится', lendül 'махнет'), частично обогащенные аллитерацией ('szökken, száll', 'lábhoz lendül').

В пятой главе «Евгения Онегина» описан бал на празднике именин Татьяны, где пары танцуют вальс и мазурку.

Однообразный и безумный,

Как вихорь жизни молодой,

Кружится вальса вихорь шумный;

Чета мелькает за четой.

(Евгений Онегин, V: 41)
Egyforma, forró szédületben,

Mint ifjú szívek vihara,

Valcer viharzik gyors ütemben,

Pár pár után suhan tova.

(А. Галгоци)

«Вальса вихорь шумный» передан в виртуозном звучании четырех строк, в ускоренном ритме (пиррихии на третьей стопе), круговым чередованием 
передних и задних гласных $a, u, o, y$, аллитерацией (вальса вихорь) и повтором (чета мелькает за четой). В переводе А. Галгоци динамизм вальса выражается в гармоническом единстве аллитераций и слов со значением бурного движения.

В той же бальной сцене гремит старинная мазурка:

Мазурка раздалась. Бывало,

Когда гремел мазурки гром

В огромной зале всё дрожало,

Паркет трещал под каблуком,

Тряслися, дребезжали рамы;

(Евгений Онегин, V: 42)
Vidám mazúrhang csalogatja

A tánczost. Hajdan ropogott

A termek rengő padolatja,

S megrezgeté az ablakot

A sarkak dörgő dobogása.

(К. Берци)

Буйный ритм мазурки выражен рядом сочетаний с дрожащим согласным p: гремел мазурки гром... В огромной зале всё дрожало, Паркет трещал... Тряслися, дребезжали рамы. Первый венгерский переводчик «Онегина» верно передал эту звукопись: ... ropogott A termek rengö... megrezegteté... A sarkak dörgö... И вот «укрощенный» вариант этого танца:

Теперь не то: и мы, как дамы,

Скользим по лаковым доскам.

(Евгений Онегин, V: 42)
Ma minden más: akár a hölgyek

Siklunk a parketten tova.

(А. Галгоци)

Новая мазурка характеризуется как в русском тексте, так и в переводе Априли преобладанием сонантов и глаголом скользим (= siklunk).

5. Грозный и зловещий вид движения описан в пушкинской поэме «Медный всадник»:

Погода пуще свирепела,

Нева вздувалась и ревела,

Котлом клокоча и клубясь,

И вдруг, как зверь остервенясь

На город кинулась...

И всплыл Петрополь, как тритон,

По пояс в воду погружен.
Ó, szörnyü nap!

A Néva már

A széllel szembe tört a tenger

Felé s dacolt a bösz elemmel...

És végül meghódolt az ár...

S a büszke Pétervárt, akár

Tritont, övig víz lepte már.

(А. Галгоци)

В комплексную картину изображения наводнения в Петербурге входят сравнение (как зверь остервенясь), глаголы грозных действий (свирепела... вздувалась и ревела), ударные задние гласные $о$ и $y$, губные и язычные согласные $\sigma, n, 6, \partial$, сочетания с дрожащим $p e, p o, p y$ и замечательная экспрессивная аллитерация Котлом клокоча и клубясь. Переводчику в значительной степени удалось передать звуковое мастерство оригинала при помощи аллитераций и ассонансов ( $A$ Néva már // A széllel szembe tört a tenger // Felé $s$ dacolt a bösz elemmel), а также экспрессивных лексических элементов (bögött, fortyogott). 
Стоит сопоставить данный отрывок с описанием наводнения реки Тиса у Шандора Петёфи:

...Mint az örült, ki letépte láncát,

Vágtatott a Tisza a rónán át,

Zúgva, bőgve törte át a gátot,

El akarta nyelni a világot!
Тиса будто цепи сорвала, Всю плотину в щепки разнесла, Разлилась, не ведая предела, Проглотить весь мир она хотела.

(В. Левик)

Разбушевавшаяся река одушевляется и в венгерском стихотворении только не как зверь, а как сумасшедший, сорвавший свои цепи. И в венгерском тексте река прорвала дамбу «ревя» и «рокоча» (zúgva, bögve).

В той же поэме описан бред помешанного Евгения, которому чудится, что его преследует ожившая статуя Петра:

Бежит и слышит за собой

Как будто грома грохотанье

Тяжело-звонкое скаканье

По потрясенной мостовой.

И, озарен луною бледной,

Простерши руку в вышине,

За ним несется Всадник Медный

На звонко-скачущем коне;

И во всю ночь безумец бедный,

Куда стопы ни обращал,

За ним повсюду Всадник Медный

С тяжелым топотом скакал.
- Rohanni kezd, amerre lát,

- És minthacsak az ég dörögne,

Mindegyre hallja a mögötte

Dübörgő hangos vágtatást.

$\mathrm{S}$ míg sápadt Hold tekint a tájra,

A szunnyadó utcák során

A Rézlovas száguld utána

Csattogva vágtató lován;

$\mathrm{S}$ szegény bolond lihegve, fújva,

Bármerre, bárhová futott,

A Rézlovas, karját kinyújtva,

Folyton mögötte vágtatott.

(А. Галгоци)

Важную роль играет здесь ритм: в 8 строках (из 12) ямб заменен пиррихием в третьей стопе, среди них в 3 строках пиррихий стоит и на первой стопе. Динамизм текста создают 4 ритмических варианта четырехстопного ямба; только две строки являются полными ямбами: они изображают скачку Статуи (За ним несется Всадник Медный... За ним повсюду Всадник Медный). Грохот скачки коня передают ударные гласные $о$, сочетания грома грохотанье... звонкое скаканье, а также аллитерации безумеи бедный... С тяжельмм топотом. В переводе половина строк - чистые ямбы; начальные спондеи в пяти строках несколько отягчают ритм (És minthacsak... Csattogva vágtató lován... Bármerre, bárhová futott). Звукопись русского текста передан звукоподражающими глаголами (dörögne... dübörgö... csattogva) и аллитерациями (S szegény bolond... Bármerre, bárhová futott... A Rézlovas, karját kinyújtva...).

6.

Весенняя гроза

Люблю грозу в начале мая,

Когда весенний, первый гром,

Как бы резвяся и играя,

Грохочет в небе голубом.
Tavaszi vihar

De szép az első égi lárma, mikor májusi dörejek mintegy csintalankodva, játszva teledübörgik az eget! 
Гремят раскаты молодые,

Вот дождик брызнул, пыль летит,

Повисли перлы дождевые,

И солнце нити золотит.

С горы бежит поток проворный,

В лесу не молкнет птичий гам,

И гам лесной и шум нагорный -

Всё вторит весело громам.

Ты скажешь: ветреная Геба,

Кормя Зевесова орла,

Громокипящий кубок с неба,

Смеясь, на землю пролила.

(Тютчев, 1828)
Zeng-zúg a menny ifjú haragja, por röpül, halk permet szitál, az eső szálain aranybavont gyöngyök milliója áll.

Fut a hegyről a fürge zajlás!

De dal és fütty sem hallgat el: a dörejre patakmorajlás és erdei koncert felel.

Azt hinnéd: Zeus sasát itatva

Hébe, szeles égi cseléd, nevetve földre zúdította viharral-habzó serlegét.

Это наиболее известное антологическое стихотворение Ф. И. Тютчева представляет собой настоящую малую симфонию весенних шумов. В четырехстопном ямбе реализованы четыре ритмических вариации. Почти в половине строк ямб заменен пиррихием в третьей стопе, что́ придает стиху особый взлет. Инструментовка играет большую роль в тексте. Первые раскаты весенней грозы переданы сочетаниями гра, гре, гро, ep, pe; шум весеннего дождя изображен сочетаниями $\sigma p b l, n b l, n o, n e$. Экспрессивное звучание текста усиливают звукоподражательные глаголы грохочет, гремит, глаголы движения летит, бежит, существительные гам и шум, и не в последнюю очередь, замечательный гапакс громокипящий кубок.

В переводе Л. Сабо ямбы представлены только в $36 \%$ стоп; в двух стихах ни одного ямба нет (De dal és fütty sem hallgat el... és erdei koncert felel); спондеи, пиррихии и хореи составляют почти две трети стоп. Вместе с тем в венгерском тексте обнаруживается характерный для венгерской поэзии двойной ритм: текст может восприниматься как чередующиеся двухтактовые девяти- и восьмисложные стихи: De szép az elsö / égi lárma, // mikor májusi / dörejek... (5+4// 5+3). Инструментовка представлена в переводе аллитерациями (mikor májusi ... mintegy; por röpül... permet szitál...; fut... a fürge zajlás), звукоподражательными словами (dörejek... teledübörgik... patakmorajlás). Заключительная строка - nevetve földre zúditotta / viharral habzó serlegét - полностью адекватна оригиналу: это настоящая trouvaille переводчика.

7.

Осенний вечер

Есть в светлости осенних вечеров Умильная, таинственная прелесть: Зловещий блеск и пестрота дерев, Багряных листьев томный, легкий шелест,

Туманная и тихая лазурь

Над грустно-сиротеющей землею,
A szép őszi estékben

A szép őszi estékben valami titokzatos és megható varázs van. A fák rikító, szilaj színei a harsányrőt lomb a halk hervadásban,

a komorodó, fáradt föld felett a kék ég s a fátyolnyi köd az arcán, 
И, как предчувствие сходящих бурь, Порывистый, холодный ветр порою,

Ущерб, изнеможенье - и на всем

Та кроткая улыбка увяданья, Что в существе разумном мы зовем Божественной стыдливостью страданья.

(Тютчев, 1830) a le-lecsapó, borzongó szelek, melyek mögött már tél sejlik s vad orkán,

mind hanyatlás, $s$ mindenen ott a tünt élet szelíd mosolya, búcsufénye az, amit embernél úgy nevezünk, hogy: a fájdalom fenséges szemérme.

(Л. Сабо)

В этих стихах на высоком художественном уровне осуществлено пушкинское требование «союза звука, чувства и думы». Стихотворение написано в пятистопном ямбе, при этом почти в одной трети текста ямбы заменены пиррихиями, а в семи строках пиррихи встречаются и во второй, и в четвертой стопе, что придает тексту колыхающую, певучую интонацию. Инструментовка стихотворения играет более скромную роль по сравнению с лексическими средствами изображения осенней красочности. В первых четырех строках преобладающие передние гласные $e$ и $u$ рисуют свет и цвета осенних вечеров. В 7-й и 8-й строках сочетания pe, po, pbl, ypb как бы предвещают приближение бури. Стихотворение заканчивается аккордом на тройное сочетание $\mathrm{cm}$. В стихотворном тексте настоящий парад атрибутивных конструкций, в которых органически соединено изображение осенних красок и шумов с их эмоциональным восприятием (умильная, таинственная прелесть осенних вечеров; зловещий блеск... дерев; томный шелест листьев; грустносиротеющая земля), и над всей этой синтетической образно-эмоциональной картиной - кроткая ульбка увяданья, напоминающая божественную стылливость человеческого страдания.

В переводе метр текста весьма расслаблен: ямбы составляют меньше одной трети стоп, они обильно заменены спондеями, пиррихиями и хореями. В одной строке ямб появляется только в последней стопе (a komorodó fáradt föld felett), и есть строка, в которой вообще нет ямба (a le-lecsapó borzongó szelek). Для инструментовки венгерского текста удачны аллитерации в 4-й и 5-й строках (a harsányröt lomb a halk hervadásban, / a komorodó fáradt föld felett), а также в 8-10 строках (melyek mögött már tél sejlik... mind hanyatlás... a tünt élet szelíd mosolya), и в особенно экспрессивном заключительном стихе: a fájdalom fenséges szemérme.

8.

...Милый лес, где я мальчонкой

Плел из веток шалаши,

Где однажды я теленка,

Сбившись с ног, искал в глуши...

Полдень раннего июня

Был в лесу, и каждый лист,

Полный, радостный и юный,

Был горяч, но свеж и чист.
Kedves erdő, merre-hol vagy?

Hajdan lombos sátrakat

Fontam benned, pici borjat

Hajszoltam a fák alatt...

Forró júniusi délben

A bozótos áthevült,

$\mathrm{S}$ minden fiatal levélen

Tiszta, édes öröm ült. 
Лист к листу, листом прикрытый,

В сборе лиственном густом

Пересчитанный, промытый

Первым за лето дождем.

И в глуши родной, ветвистой,

И в тиши дневной, лесной

Молодой, густой, смолистый,

Золотой держался зной.

И в спокойной чаще хвойной

У земли мешался он

С муравьиным духом винным

И пьянил, склоняя в сон.

И в истоме птицы смолкли...

Светлой каплею смола

По коре нагретой елки,

Как слеза во сне, текла...

(Василий Теркин. О себе)
Lomb a lombon sürü sátor,

Zöldbe fúló ágasok -

És az első nyári zápor

Minden lombot átmosott.

És a meghitt, tarkamintás,

Dús vadonban ősi csend,

És a csendben ifju, gyantás

Arany forróság pihent,

S csöndes lúcok közt az árnyban

Lágyan elkeverve szállt

Hangyák boros illatában,

$\mathrm{S}$ ittas álom fogta át.

Már madárka sem csicsergett,

Ült a tikkadt lomb között,

$\mathrm{S}$ álmok tünde könnye pergett

Langyos kérgen: gyantacsöpp...

(Л. Кардош)

Это прекрасное лирическое отступление из поэмы Александра Твардовского «Василий Теркин» продолжает лучшие традиции описания природы (в частности, леса) в русской поэзии. Точное и верное описание июньского леса, дышащего «муравьиным винным духом» своей дождем промытой листвы - глубоко эмоционально, и его главный секрет в том, что все звучание этого текста передает - тишину. Цитированный отрывок (как и вся поэма) написан в четырехстопном хорее, но полноударными являются только 4 строки из 24! Хорей заменен пиррихием у половины строк в третьей стопе стиха, и это придает тексту особую убаюкивающую, напевную интонацию.

Инструментовка стихов следует пушкинской традиции: экспрессивные звуковые средства органически соединены с семантикой слов, создавая яркий эмоциональный ореол изображения. Чередующиеся передние и задние ударные гласные $e, u, o, y, b l$, сочетания $n p u, n e p, n p o$, частично аллитерированные ла, ле, ли, ло, преобладающие сонанты $\boldsymbol{M}$ и $\boldsymbol{H}$ в пятой строфе - все это воплощено в виртуозном синтезе ощущений от знойной лесной глуши.

В переводе, сделанном выдающимся литератором Л. Кардошем, хореи встречаются всего в 48\% стоп; большое количество спондеев (почти 37\%) несколько замедляет венгерский текст, в котором также проявляется возможность двойной ритмизации: он легко воспринимается как ряды пятнадцатисложных двухтактовых стихов: Kedves erdö, merre-hol vagy? / Hajdan lombos sátrakat // Fontam benned, pici borjat // Hajszoltam a fák alatt... (4+4/4+3 // $4+4$ / 4 +3). Переводчик сохраняет аллитерацию (Lomb a lombon sürü sátor), удачно передает мелодичность оригинала с помощью преобладания сладкозвучных сонантов $m, n, n y:$ És a meghitt, tarkamintás, / Dús vadonban ösi csend, // És a csendben ifju, gyantás / Arany forróság pihent. При этом звукопись - как у Александра Твардовского - гармонически связана с экспрессивными лек- 
сическими элементами: ifju, gyantás / Arany forróság 'молодой, смолистый, золотой зной'; Lágyan elkeverve szállt / Hangyák boros illatában, / S ittas álom fogta át У земли мешался он / С муравьиным духом винным / И пьянил, склоняя в сон.

Разумеется, приведенные мною примеры сами по себе не разрешают теоретическую проблему художественного перевода поэзии. Но они могут содействовать признанию перевода особой функцией литературы (см. PAZ 2007: 225), которая в значительной мере способствует обмену культурными ценностями между народами и тем самым их взаимному пониманию.

\section{Источники}

ПЕтЁФИ 1953 = ПЕтЁФИ Ш. Избранное. Москва: «Художественная литература», 1953. Пушкин $1957 \mathrm{a}=$ Пушкин А. С. Медный всадник. В кн.: Пушкин А. С. Полное собрание сочинений в 10 томах. Т. 4. Москва: Издательство АН СССР, 1957. 375-396.

Пушкин $1957 \mathrm{~b}=$ Пушкин А. С. Евгений Онегин. В кн.: Пушкин А. С. Полное собрание сочинений в 10 томах. Т. 5. Москва: Издательство АН СССР, 1957. 5-213.

ТВАРДОВСКИЙ 1966 = ТВАРДОВСКИЙ А. Т. ВасилИй ТеркИн. В кн.: ТВАРДОВСКИЙ А. Т. Собрание сочинений в 5 томах. Т. 2. Москва: «Художественная литература», 1966.

Тютчев 1957 = Тютчев Ф. И. Полное собрание стихотворений. Ленинград: «Советский писатель», 1957.

E. FeHÉR-LAtor 1966 = Klasszikus orosz költők. Válogatta E. Fehér Pál és Lator László. Budapest: Európa, 1966.

GALGÓcZY 2004 = GALGÓcZY Árpád: Szerettem Önt. Válogatás Alekszandr Puskin költészetéböl. Budapest: Eötvös, 2004.

PetÖFI 1953 = Petőfi Sándor összes költeményei. 2. kötet. Budapest: Szépirodalmi Könyvkiadó, 1953.

PUSKIN 1959 = PUSKIN: Jevgenyij Anyegin. Ford.: Áprily Lajos. Budapest: Európa, 1959.

TvardovszKiJ 1952 = Tvardovszkis: Vaszilij Tyorkin. Ford.: Kardos László. Budapest: Új Magyar Könyvkiadó, 1952.

\section{Литература}

Чуковский 1964 = Чуковский К. Высокое искусство. Москва: «Искусство», 1964.

Эткинд 1963 = Эткинд Е. Поэзия и перевод. Москва-Ленинград: «Советский писатель», 1963.

JózAn-Jeney-Hajdú 2007 = JózAn Ildikó, Jeney Éva, HaJdú Péter (szerk.): Kettős megvilágitás. Fordításelméleti írások Szent Jeromostól a 20. század végéig [Двойное освещение. Работы по теории перевода от Блаж. Иеронима до конца XX века]. Budapest: Balassi, 2007.

PAZ 2007 = PAZ Octavio: A fordítás - irodalom és irodalmiság [Перевод - литература и литературность]. In: JÓZAN-JENEY-HAJDÚ 2007: 219-231. 